\title{
When an orchestra misses its harmony (Or how I learnt to work with my supervisors)
}

Mai Khanh Tran is a PhD student in the Department of Marketing at the University of Birmingham

PRELUDE

The last note of Mendelssohn's Violin Concerto Op. 64 flew in the air, I dropped to the world of reality. After being indulged by this beautiful orchestral work, I recognised that my PhD life was a sonata in which the harmony element was mostly missing. I am not talking about the structure of my thesis or my theoretical contributions. I am reflecting on the experience of working with my three supervisors.

Let's imagine research students are the composers of theory who are still learning to compose. We get exposed to different materials and try out various instruments. We experiment with a wide range of styles and then identify our périodique and area. While we could learn from so many people, supervisors invariably have predominant roles as our conductors. They are instructors and influencers of our research interest, direction, and methodology. They can be our role models, collaborators, and co-authors. In order to learn how to fit into the academic community, we need their guidance, support and advice. Having great supervisors for our theses is similar to having all the orchestral sections from which to enrich our composition. Welcoming more brains to the team is as wonderful as having a palette of sounds from strings, woodwinds, percussions, and brass sections to explore various opportunities and get closer to the sense of virtuoso. When we all work in harmony, masterpieces are the potential outputs. However, if one section is out of tune, the whole piece falls flat.

My doctoral journey at a UK University did fall flat a couple of times, usually right before or right after a peak (an achievement or an important milestone). However, rhythmic shifts are part of an orchestral piece, aren't they? Through this chapter, you are welcome to a student-supervisor sonata with three movements: "Lost in communication", "Crashes of voices", and "Harmonious counterpoints."

\section{THE FIRST MOVEMENT: LOST IN COMMUNICATION}

The first movement of a sonata usually has a gentle start, or introduction before moving to its exposition, development, re-exposition and coda. This best represents how my first year as a doctoral student was, except the fact that I had a few reexpositions before reaching such a dramatic coda. Initially, I had difficulty in understanding what my supervisors expected of me, knowing what standard of work was required, how to respond to their feedback, and also the expected way to communicate with them both by email and in meetings. This cumulated when one of them, from my perspective, was critical of my research in my first ever presentation. Needless to say, my confidence as a researcher collapsed.

After my research proposal was accepted, I was allocated two supervisors to work with, both of whom specialised in quantitative methods. I had planned to conduct a mixed method study so I had hoped that one would have quantitative and one had qualitative expertise. However, my lead supervisor considered this would not be a problem as the second supervisor role was less important. Accordingly, 
the second one would only need to handle the paperwork, such as signing monthly meeting forms or students' application for conference funding, when the first one was away. He further explained that doctoral students worked mainly with the lead supervisors and the second supervisors' academic contribution would not affect the students' progress. As a fresh PhD student, I thought this made sense. We only have one conductor in an orchestra, don't we?

Both supervisors appeared very supportive, their feedback, mostly through emails, was positive, and they always gave me lots of compliments when reading my work. They had known me since I was a master's student, so they said that I would progress well if I kept doing what I was doing. All that was required was to "read more" and remember that a doctorate is more complicated than an MSc. I kept on reading, developing a theoretical framework and began to develop a research plan. However, after a few months, I started to feel confused about where this "read more" led me to. I thus asked for a meeting that would give me more specific, constructive feedback so that I could have a better focus. In the meeting, I presented my current research, answered their questions and then was allowed to ask questions. All seemed to be fine and they did not show any concerns at all. However, when I started to ask the questions, I was told to "read more", again. Moreover, in response to my specific questions about the research gap and the literature, the supervisors just gave me very generic answers with no further discussion or an explanation, such as "We are not so sure", "Bluntly speaking, I did not see how you could develop this research this way". The fact that they appeared suddenly disinterested in my work made me scared. I did not know if my capability of communicating was rubbish or my research was of poor quality. I blamed myself and pushed myself harder.

After the meeting, I also started to wonder if my two supervisors had actually read my work in detail. Comments such as "generally good", "very interesting", "well-articulated", "dynamic", or "promising" no longer convinced me that I was doing fine. I struggled to both develop my research from their general comments and find a way to obtain more specific feedback on my work. Since there were a few calls for conference submissions during that time, I decided to submit my work to two conferences. I spent the first Christmas break of my PhD life on reading and writing. I then asked if my lead supervisor would be willing to have his name on the submissions. When he was happy to become my co-author and check my work, I was beyond excited as this was the first time I got detailed comments on my writing. After a few months, I got accepted to both of the conferences. My first supervisor also suggested that I consider adding the second supervisor's name to the submissions. I was so pleased that, finally, both of the supervisors seemed to be happy with my work. I also felt great that I started to have more aspects of my research to discuss with my second supervisor.

Unfortunately, the happiness did not last long. A few weeks before my travel to the first conference, my department asked PhD students to present their research. They set up a panel that included academics both inside and outside my department with the intention of providing students with constructive feedback on both their academic insights and presentation. I discussed my plan of using mixed methods for my research and both of my supervisors said that I was ready to go. On the presentation day, the panel gave me good feedback on the theoretical framework and expected contributions. I also received some critical questions regarding methodology which I found very helpful. Suddenly, my second supervisor commented "I told you about the methodology, but you did 
not listen" and added that he did not see any clear contribution from my research. The criticism was mainly about not having incorporated his earlier feedback. However, the critique came as a solemn, austere trumpet sound thrown into a delicate leitmotif. I felt confused: When did he even show concern and give me advice on the methodology section? I got in a fluster when people in the room seemed to question my receptiveness. The panel members asked me in a slightly disappointing tone of voice "So we hoped you would take into consideration some of our comments?" I kept confirming how much I appreciated their suggestions, summarised what I would take away from their advice, and said thanks to everyone again and again. At the same time, I also apologised my second supervisor for not fully understanding his advice prior to my presentation. Even though my second supervisor just wished to show their objectivity in giving feedback, I was very sad. My first performance had ended badly. I came home with my confidence smashed into pieces. I certainly did not want to go to any conferences.

\section{THE SECOND MOVEMENT: CRASHES OF VOICES}

The second movement of a sonata usually has a theme and many variations. Whilst I aimed to have a "Harmony" theme for my second year of study, I ended up with a theme of "Crashes" of different voices. A chain of crashes occurred, ranging from epistemology, research directions, to working styles. My PhD composition, fortunately, still grew with the help of a new voice: my third supervisor.

I thought I had learnt how to cope with feedback and public criticism: Move on, make progress, keep harmony. I set aside all the concerns, went to both the conferences during summer, and received really good feedback. Importantly, in both conferences, I consistently received two recommendations: First, strengthen the qualitative method as this fitted my research objectives and, second, make the most of the synergy between your supervisors. A strong supervising team would help my progress and potentially support the development of have publications, both of which were crucial for me to tap into the world of academia. The idea of having a supervisor who specialised in qualitative methods dominated my mind. Just as a composition beautifully fabricated with the aid of various orchestral sections, my research - and I - could grow stronger if I had the desired expertise to join the supervising team.

The process of finding a new "voice" for my composition invited crashes of opinions. I heard so many suggestions and "lessons" from former PhD students who warned me about the risks of changing the supervising team. According to my University's regulations, each doctoral student was normally allocated only two supervisors. Therefore, if I initiated to ask for a new one, this meant my second supervisor might be replaced with potential consequences. For example, my request might result in an uncomfortable student-supervisor relationship if the current one was informed of my intention. When I proposed the idea to my lead supervisor, he comforted me by reminding me that I did not need to worry about the second supervisor and that I should avoid upsetting people. However, I was torn between two options: a harmony with my supervisors and my research progress.

In order to stop myself from getting bogged down in the dilemma, I proceeded with my data collection, becoming involved in a real-life project that was aimed to develop a technological output to 
help the young audience engage with classical music. As the project was co-developed by two renowned organisations, one is a global technology company, the other is a world-class orchestra, it was expected to create an impact at both the city and regional level. I was particularly intrigued by this research context and the variety of data emerging from the project which included music, visual data and even sketches of design. Furthermore, the fieldwork allowed me to explore various themes of research, ranging from the intersection of the arts and technology to co-innovation, experiential consumption and aesthetic engagement, all of which were fascinating topics in the marketing discipline. Unfortunately, my supervisors did not see the data good enough for a PhD due to the small number of participants. They suggested I use the project as a pilot from which I could build up my questionnaires. After several meetings, I recognised that my supervisors and I had completely different epistemological views and our discussions were of little benefit.

I discussed my current status, research direction and types of data of my research with my programme director who confirmed that having three supervisors was possible. After a few months, I was asked to go to an interview in which I would need to present my research to a professor who was an expert in cultural theory and qualitative method. I felt both excited and intimidated at the same time, as the professor was a great scholar with so many awards and well-known research projects. I had butterflies in my tummy for a week before the interview. I was scared that the professor might not like my research or my way of presenting and communicating. Contrary to my thoughts, she was interested in my research and agreed to become my third supervisor. She was very specific and explicit in giving comments and recommendations. She pointed out those aspects of my research that could be further developed to provide theoretical contributions. She offered an interesting approach to explain the research paradigm and suggestions as to how I should move forward with my data. I was so thankful when she provided me with a pool of ideas and key names in the fields so that I could explore different areas and writing styles. The whole meeting lasted no longer than forty minutes, yet I gained so much from her suggestions. My two supervisors were also very pleased that I had successfully invited the professor to join the supervising team.

Having four heads in one PhD project was as great as having a complete orchestra with four sections. My lead supervisor played the percussion, making the climactic moments with booming bass drum and lead the rhythms of the whole orchestra. My second supervisor's mountainous brass came with tremendous force. My third supervisor was the concertmaster playing the first violin and created the most eloquent and calm sound quality yet extremely lively, sparkling, and bright. I took over the woodwind section - the most whistling, wafting, merry, open, yet slightly muffled. When I started my second year, we had the first meeting of four members in which my third supervisor shared so many ideas for the whole team. Strangely enough, we rarely had a meeting of four after that. My lead supervisor suggested that, for everyone's convenience, I could contact any supervisor individually for help and then ask for an all-member-meeting when needed. Although this working style was way different from my imagination of "an orchestra of academics", I was still happy to explore possibilities and opportunities when working with each of them. 


\section{THE THIRD MOVEMENT: HARMONIOUS COUNTERPOINTS}

The third movement of a sonata is usually a vigorous, light, or playful composition with danceable melody. I was wondering if I should call my third year "The Scherzo of counterpoints" due to a series of strikes happening in my doctoral journey. These related to working style (again) between my supervisors, priority and authorship. While I breathlessly caught up with the dance of incidents, I did find that the doctoral journey provided me with unique, memorable "harmonious counterpoints" that trained me to become a skilled composer, conductor, and performer of knowledge.

I gradually found that working individually with each supervisor was unnecessarily time-consuming and extremely challenging for both myself and the supervisors. My second supervisor dropped out of the supervising team after a few weeks since he found my new direction was no longer of his interest. We decided to keep in touch and maintained a good relationship hereafter. My third supervisor thus became my second one and her responsibility in the supervising team was almost equal as my lead supervisor. As I began to work more closely with her, my research started to evolve significantly. I also enjoyed her working style: short, simple, precise, and productive. Besides her incredibly high standard of research skills, she described herself as "an academic obsessed with writing and proofreading". She spent massive time checking my writing, pointing out my weaknesses, embracing my strengths and encouraging me to develop a "poetic" writing style that fitted both my research and personality. Importantly, she recognised my interest in the arts and put it to work by guiding me on how to become an ART - an Artist, Researcher, and Teacher (Leavy, 2015).

My new second supervisor and I then decided to write a submission to a high-ranking journal. From her revision and contributions, I started to understand what it really meant by being an academic, and what professionalism was. The writing process last for approximately four months and it was a real eye-opener. My new second supervisor always managed to respond to me within a day with very detailed feedback and guidance that rigorously enhanced my data analysis and writing. With my utmost respect, I put her name as the lead author for her invaluable contributions. To my biggest surprise, she said that this paper was my research and what she did was just a touch of help, and that I should be the corresponding author and she was happy to be the second author. When being informed of the potential submission, my lead supervisor was also happy to give me his comments on the literature review, which was his field of research. However, he also suggested that, as the lead supervisor he might be the second author, citing his contribution to my academic development since I started my doctorate. He also said that I needed to discuss this with my new second supervisor of a few months. My new supervisor explained that the order of the co-authors of a publication should be based on the relative contributions. I felt that I had a heart attack on that day. This was my first ever submission and I did not even know if it could get through the desk reject, yet I already felt a huge pressure on my shoulder and my chest. After checking the University protocol, I was confident that my new second supervisor deserved to be the second author of the submission. After my explanation to my lead supervisor, the co-authorship of the paper was sorted. 
Our submission was not desk rejected and began several rounds of the peer-review. However, the stronger our submission grew, the weaker our orchestration became. I never got a meeting with both of my supervisors together unless it was my annual progress review. My two supervisors held different views and suggestions for my research. While each direction had its own strength, I struggled to put these two separate, opposite ideas together. When entering my write-up stage, I felt that such differences that would lead me to nowhere. I therefore decided to follow my second supervisor's direction as this offered a perfect fit for my research. Although I knew I upset my lead supervisor for not incorporating enough of his advice into my thesis, I believed the consistency and associated research quality should be my priority. My lead supervisor agreed and supported me in this journey.

As I was finalising this book chapter, I successfully submitted and defended my thesis and both of my supervisors were very happy celebrating the moment with me. A PhD journey is surely not a fairy tale, rather, an orchestral composition full of explorations of sounds (voices), new materials, harmonious counterpoints and changes in pitches and rhythms. A dark tone in a movement does not mean the whole composition is tragic. My act of composing a doctoral thesis has helped train me to feel less afraid and to embrace whatever is in my path.

\section{LESSONS FOR KEEPING YOUR DOCTORATE ON TRACK}

- A harmonious relationship is important, yet it does not mean you have to compromise.

- "Your PhD is your responsibility, and your progress is key". If you need to make any changes in order to make progress, do it! You do not commit any crime by proposing changes for the greater good.

- If you do not feel that a supervisor's contributions are relevant to your progress, consider using the differences in academic standpoints as a reason to change supervisors. Personal emotion is not a convincing reason to request for changes in an academic, professional environment.

- If you are torn between two supervisors' directions, you can seek advice from your programme director, or the person in charge of doctoral students. You can use an annual progress review as a platform to emphasise how you need to have a clear direction in research in order to complete in the planned time frame.

- If you and your supervisors are co-authoring a publication, you all need to be clear and agree responsibilities, contributions of each author, and the order of the authors accordingly. Most Universities have codes of practices on this.

\section{REFERENCES}

Leavy, P. (2015). Method meets art: Arts-based research practice. Guilford Publications. 